\title{
Simulation of Flow in Turbopump Vaneless and Vaned Diffusers with Fluid Injection*
}

\author{
ALI OGUT ${ }^{\dagger}$ and DIEGO GARCIA PASTOR \\ Department of Mechanical Engineering, Rochester Institute of Technology, Rochester, NY 14623, USA
}

(Received 24 April 1998; In final form 21 July 1998)

\begin{abstract}
In future space missions by NASA there will be a need for "Space Transfer Vehicles" to perform varying orbital transfers and descents. This requires engines capable of producing different levels of thrust. To accomplish this, the turbopumps employed in these engines should efficiently provide a wide range of flow outputs. However, current fuel and oxidizer turbopumps with vaned diffusers do not perform efficiently at off-design (low) flow rates mainly due to flow separation in the vaned diffuser.

This paper evaluates the effectiveness of boundary layer control by fluid injection (blowing) for suppressing or eliminating the flow separation in a vaned diffuser. A 3-D flow model including vaneless and vaned diffusers of a liquid hydrogen $\left(\mathrm{LH}_{2}\right)$ turbopump is studied using the CFD code FIDAP. The paper presents the results of the model at design and offdesign flow conditions.

The model results showed that flow separation occurs at the top or suction surface of the vaneless diffuser and at the bottom or pressure surface of the vaned diffuser at off-design flow rates. When fluid injection was applied through the bottom surface of the vaned diffuser, the separated flow region was reduced almost entirely, resulting in an increase in pressure recovery of up to $21 \%$ with varying fluid injection rates. Results also showed that there is an optimum injection rate which is most effective in reducing or eliminating the region of flow separation.
\end{abstract}

Keywords: CFD, Turbopump, Diffuser, Flow separation, Boundary layer control, Fluid injection

\section{INTRODUCTION}

The future space missions planned by NASA will use "Space Transfer Vehicles" to perform orbital transfer missions and Lunar/Mars transfers and descents. In order to do this efficiently, the vehicle must have a deep-engine throttling capability that can be obtained by designing a high performance Liquid Hydrogen $\left(\mathrm{LH}_{2}\right)$ turbopump which can efficiently output different flow rates or operate at off-design conditions.

The current designs of turbopumps with vaned diffusers do not perform efficiently at off-design flow rates due to flow separation and stall in the

* This paper was originally presented at ISROMAC-7.

${ }^{\dagger}$ Corresponding author. 
vaned diffuser. Particularly, at low flow rates, impeller discharge effects and increased boundary layer blockage in the vaneless and vaned diffusers lead to flow separation in the vaned diffuser.

The subject of this paper is to provide an insight into the effectiveness of fluid injection as a boundary layer control method in suppressing or eliminating flow separation in the vaned diffuser at off-design flow conditions. The effectiveness of this method will be demonstrated by obtaining a pressure recovery significantly higher with fluid injection than without at off-design flow conditions. The intent is to demonstrate the applicability of boundary layer control by fluid injection method for improving the performance of a three-dimensional vaned diffuser and to use the results to modify the diffuser design for improved turbopump performance at off-design flow conditions.

The model employed here includes the addition of the vaneless diffuser section to the previously studied vaned diffuser model by Ogut and Yoshida (1994), so that a more realistic model which accounts for the impeller discharge effects can be studied. In addition, for the control of boundary layer, fluid injection is used instead of fluid suction.

A finite-element based code, FIDAP was used for flow analysis.

\section{BACKGROUND}

A vaned diffuser is one of the basic components of a turbopump. Its function is to convert inlet dynamic pressure (kinetic energy) to a static pressure rise. For subsonic flows this is accomplished by decelerating the fluid particles with a continuos increase of the diffuser cross-sectional area. The desired effect is to recover as much of the inlet dynamic pressure as possible under a steady flow condition.

However, since the diffuser performs in an adverse pressure gradient field, operating it at off-design conditions, such as at low flow rates, often leads to flow separation and stall.

Lariviere (1989), and Lariviere and Prueger (1989), through experimental work, has shown that high performance multistage turbopumps with vaned diffusers often develop stall related instabilities at low (off-design) flow rates. For efficient overall pump performance the stall and flow separation in these diffusers must be prevented. This requires new design concepts and improved prediction methods which can lead to the necessary design modifications in the diffuser geometry.

\section{Diffuser Performance}

The subject of fluid-flow in diffusers contains many references. Particularly Kline and Fox (1962) addressed the issue of diffuser stall in detail and defined four major areas of diffuser stall known as "no appreciable stall", "large transitory stall", "fully developed two-dimensional stall", and "jet flow". Based upon $N / W 1$ and $2 \theta$ of a vaned diffuser, they developed a chart showing these four stall regions. This chart has been useful in the design of stall-free vaned diffusers.

A diffuser performance depends upon its particular geometry, and because it operates with an adverse pressure gradient field, its efficiency is limited. The geometry of a diffuser is fully specified by the aspect ratio $b / W_{1}$ and any two of the $L / W_{1}$, $N / W_{1}$, and the area ratio, $W_{2} / W_{1}$. The performance of a diffuser is specified by the pressure recovery coefficient:

$$
C_{p}=\frac{p_{2}-p_{1}}{1 / 2 \rho V_{\mathrm{t}}^{2}}
$$

where $p$ is the pressure and $V_{\mathrm{t}}$ is the mean throat velocity. An ideal pressure recovery coefficient can also be defined and can be shown to be:

$$
C_{p, \text { ideal }}=1-\left(\frac{1}{\mathrm{AR}}\right)^{2}
$$

where $A R$ is the area ratio.

\section{Turbulent Flow Model}

The turbulent flow can be described at every point by Navier-Stokes (N-S) equations. For the flow 
in a diffuser with the assumptions of steady, incompressible, isothermal and Newtonian flow conditions the time-averaged (the usual overbar symbol omitted except for the fluctuating quantities) N-S equations for the conservation of mass and momentum can be written as:

$$
\begin{gathered}
\frac{\partial u_{i}}{\partial x_{j}}=0 \\
\rho\left[u_{j} \frac{\partial u_{i}}{\partial x_{j}}\right]=-\frac{\partial p}{\partial x_{i}}+\rho F_{i} \\
+\frac{\partial}{\partial x_{j}}\left[\mu\left(\frac{\partial u_{i}}{\partial x_{j}}+\frac{\partial u_{j}}{\partial x_{i}}\right)-\rho \overline{u_{i}^{\prime} u_{j}^{\prime}}\right]
\end{gathered}
$$

The addition of $-\overline{\rho u_{i}^{\prime} u_{j}^{\prime}}$ (known as the Reynolds stress) to the momentum equation prevents the solution of the above set of equations. Consequently, the two-equations $k-\varepsilon$ turbulence model is usually employed to facilitate the solution.

The $k-\varepsilon$ model leads to the use of eddy viscosity defined by:

$$
\mu_{\mathrm{t}}=C_{\mu} \frac{\rho k^{2}}{\varepsilon}
$$

along with transport equation for $k$ and $\varepsilon$ :

$$
\rho\left[u_{j} \frac{\partial k}{\partial x_{j}}\right]=\frac{\partial}{\partial x_{j}}\left(\frac{\mu_{\mathrm{t}}}{\sigma_{k}} \frac{\partial k}{\partial x_{j}}\right)-\rho G-\rho \varepsilon
$$

and

$$
\rho\left[u_{j} \frac{\partial \varepsilon}{\partial x_{j}}\right]=\frac{\partial}{\partial x_{j}}\left(\frac{\mu_{\mathrm{t}}}{\sigma_{\varepsilon}} \frac{\partial \varepsilon}{\partial x_{j}}\right)-c_{1} \rho \frac{\varepsilon}{k} G-c_{2} \rho \frac{\varepsilon^{2}}{k}
$$

where $G$ is the shear generation term defined as:

$$
G=-\overline{u_{i}^{\prime} u_{j}^{\prime}} \frac{\partial u_{i}}{\partial x_{j}}
$$

and modeled as:

$$
G=\frac{\mu_{t}}{\rho}\left(\frac{\partial u_{i}}{\partial x_{j}}+\frac{\partial u_{j}}{\partial x_{i}}\right) \frac{\partial u_{i}}{\partial x_{j}}
$$

In these equations: $C_{\mu}, c_{1}, c_{2}, \sigma_{k}$, and $\sigma_{\varepsilon}$ are taken as $0.09,1.44,1.92,1.0$ and 1.3 respectively.

The $k-\varepsilon$ model used is only applicable in fully turbulent (high Reynolds number) region. The solution is extended to the wall region by employing Law of the Wall models.

The Law of the Wall models are developed by using the dominant shear analysis. In the near-wall region the total shear stress containing the combined effects of laminar and turbulent shear is constant. In the viscous sublayer $\left(y^{+}<5\right)$, the laminar shear is dominant:

$$
\tau_{\text {tot }}=\mu\left(\frac{\partial u}{\partial y}\right)
$$

which by appropriate substitutions and rearrangements leads to:

$$
\frac{u}{u^{*}}=\frac{\rho u^{*} y}{\mu}
$$

which by definition can be expressed as:

$$
u^{+}=y^{+} .
$$

In the fully developed turbulent region just beyond $y^{+}=30$, where the turbulent shear is dominant, the total shear is still constant and can be set equal to $\tau^{*}$ :

$$
\tau^{*}=\rho u^{*}=-\overline{\rho u^{\prime} v^{\prime}} .
$$

Using dimensional reasoning, Eq. (13) can be written in the form of a velocity profile:

$$
u^{+}=\frac{1}{\kappa} \ln \left(E y^{+}\right)
$$

where $\kappa=0.41$ and is known as the von Karman constant and $E$ is an empirical constant (roughness parameter) found to be 9.0 for smooth walls.

Similarly, from dimensional analysis the equations for $k$ and $\varepsilon$ for the wall region are given by:

$$
k=C_{\mu}^{-0.5} u^{* 2}
$$


and

$$
\varepsilon=\frac{u^{* 3}}{\kappa y} .
$$

Equations (12), (14), (15) and (16) are the basis of the Law of the Wall models. These equations are employed in the diffuser flow analysis.

\section{Boundary-Layer Control by Fluid Injection}

The reduction or elimination of flow separation and stall in a vaned diffuser has been investigated as an alternative to modifying its geometry. One approach that has been used for correcting flow separation is boundary layer control by fluid injection. This method consists of near-wall momentum addition to re-energize the near-wall fluid particles which are being retarded in the boundary layer. This can be accomplished in active or passive manner.

In the case of the active method, a fluid is injected parallel to the wall to augment the shear-layer momentum or normal to the wall to enhance the mixing rate. Either a blower or the pressure differential that exits in the passage is utilized to inject the fluid into the retarded region of the boundary layer.

Schwendemann and Sanders (1982) showed that the efficiency of the fluid injection depends on the momentum of the injected fluid and the distance between the injection slit and the boundary layer separation point. It is indicated that for the injection to be effective, this distance must be long enough to allow sufficient time for the mixing process to facilitate the momentum transfer from the jet to the boundary layer. At the same time it should be short enough to ensure that the new boundary layer developing between the wall and the jet does not grow to the point of separating from the wall. In addition the jet maximum velocity decreases with an increase of this distance, which tends to make the process inefficient.

A literature search provided few references on the use of fluid injection for control of boundary layer growth in a diffuser. Ball (1983) experimentally showed that using either fluid suction or injection can improve the performance of a diffuser Bahl (1985) investigated the two-dimensional boundary layer separation and attachment due to small blowing through a transverse porous slot. His work showed that higher blowing velocities can cause the formation of a separation region upstream of the jet.

\section{The FIDAP Code}

In this study, FIDAP was used to predict local flow separation, regions of stagnation, and secondary flow patterns within the vaneless and vaned diffusers of a $\mathrm{LH}_{2}$ turbopump.

FIDAP is a finite-element based CFD code. It provides several turbulence models for solving the Reynolds averaged Navier-Stokes equations for turbulent flow. In this study, the solution is made possible by employing the two-equation $k-\varepsilon$ turbulence model. Eight-noded brick elements were selected for the continuum flow to reduce the computational time required to obtain a solution. For greater accuracy of turbulent modeling, fournoded quadrilateral elements were chosen for the near-wall region. These elements invoke the nearwall model within FIDAP that connects the sharp gradients in the near-wall region with the free stream region. The $3-\mathrm{D}$ model consisted of 45,000 grid points.

\section{Application}

The diffuser flow passage being studied is a scaledup model (scale factor: 10) of the diffusing crossover section of a NASA $\mathrm{LH}_{2}$ turbopump (Model: MK49-F). This turbopump has 17 interstage radial continuous crossover passages per stage. A passage consists of a vaneless diffuser, a three-dimensional vaned diffuser (upcomer), followed by a turning channel which is followed by a downcomer diffuser. The turbopump vaned diffuser has a square throat area with $25.4 \mathrm{~mm}$ in height, expanding to a square discharge area with a height of $42 \mathrm{~mm}$ with an half divergence angle of $6^{\circ}$ and an axial length of $230 \mathrm{~mm}$. 
In this study, the vaned diffuser along with the vaneless diffuser and turning channel were modeled. As indicated earlier, the inclusion of the vaneless diffuser is important since this allows the study of impeller discharge effects as well as the resulting flow structure in the vaneless diffuser. The 3-D mesh plot showing the diffusers with turning channel is given in Fig. 1.

The inlet to the vaneless diffuser and the outlet from it in the circumferential direction are characterized by cyclic symmetry so periodic boundary conditions are used at these planes. In order to properly simulate impeller outlet (vaneless diffuser inlet) conditions, the flow was introduced into the vaneless diffuser at velocities that would exist at the impeller blade trailing edge. These velocities were determined using a meanline pump performance analysis program and listed in Table I for the flow rates studied.

Although the impeller blade wake effects introduce periodic unsteadiness at the vaned diffuser inlet, the work of Muggli et al. (1996) reported that no substantial difference can be found between the steady simulation and the time-averaged of the unsteady simulation of flow in a vaned diffuser of a pump. As a result, a steady simulation in the present study was considered to be satisfactory.

The model studies were made at design flow rate with no injection and at $60 \%$ off-design flow rate with and without injection. These off-design flow

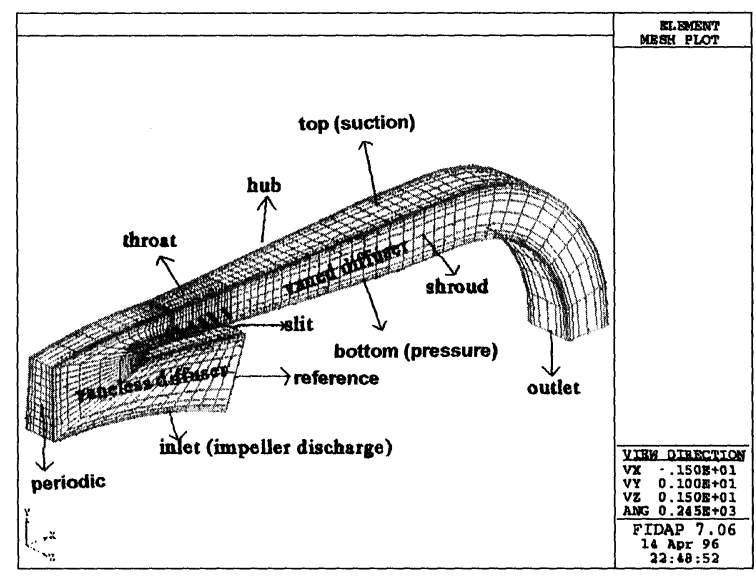

FIGURE 1 Diffuser mesh
TABLE I Flow parameters

\begin{tabular}{lcccc}
\hline $\begin{array}{l}\text { \% of } \\
\text { design flow }\end{array}$ & $\begin{array}{c}\text { Mass flow } \\
(\mathrm{kg} / \mathrm{s})\end{array}$ & $\operatorname{Re}$ & $\begin{array}{c}V_{r} \\
(\mathrm{~m} / \mathrm{s})\end{array}$ & $\begin{array}{c}V_{\theta} \\
(\mathrm{m} / \mathrm{s})\end{array}$ \\
\hline 100 & $3.98 \times 10^{-4}$ & $3.074 \times 10^{5}$ & 29.35 & 517.7 \\
60 & $2.39 \times 10^{-4}$ & $1.845 \times 10^{5}$ & 17.61 & 540.0 \\
\hline
\end{tabular}

TABLE II Slit boundary conditions at off-design flow rate

\begin{tabular}{lcccr}
\hline $\begin{array}{l}\text { \% of design } \\
\text { flow }\end{array}$ & $\begin{array}{c}\text { Injection } \\
\text { rate }\end{array}$ & $\begin{array}{c}\text { Injection } \\
\text { flow }(\mathrm{kg} / \mathrm{s})\end{array}$ & $\begin{array}{c}V_{x} \\
(\mathrm{~m} / \mathrm{s})\end{array}$ & \multicolumn{1}{c}{$\begin{array}{c}V_{y} \\
(\mathrm{~m} / \mathrm{s})\end{array}$} \\
\hline \multirow{3}{*}{60} & $3 \%$ & $7.159 \times 10^{-6}$ & $7.8 \times 10^{-3}$ & $5.46 \times 10^{-3}$ \\
& $7 \%$ & $1.67 \times 10^{-5}$ & $1.82 \times 10^{-2}$ & $1.274 \times 10^{-2}$ \\
& $10 \%$ & $2.386 \times 10^{-5}$ & $2.59 \times 10^{-2}$ & $1.82 \times 10^{-2}$ \\
\hline
\end{tabular}

rates were selected since the work of Lariviere and Prueger (1989) have shown that stall related instabilities occur in the vaned diffuser in the flow range less than $76 \%$ of the design flow.

\section{Fluid Injection}

The fluid injection was applied through the bottom or pressure surface of the vaned diffuser. The fluid was injected at an angle of $35^{\circ}$ from the diffuser centerline through each of the six slits, two before and four after the diffuser throat (Fig. 1). Slits were $2 \mathrm{~mm}$ in width and placed $1.25 \mathrm{~cm}$ apart. They were positioned along the diffuser wall such that they were shorter in the flow direction and ran the width of the diffuser.

The previous work by Ogut and Yoshida (1994) showed that injection rates between $3 \%$ and $10 \%$ of the inlet mass flow rate would be effective. The injection rates selected in this study were $3 \%, 7 \%$, and $10 \%$ of the inlet mass flow rate. The total injection rate was distributed equally across the six available slits with the velocity of the fluid at each slit being equal. The boundary conditions at slits are given in Table II for the off-design case.

\section{RESULTS AND DISCUSSION}

\section{Flow Patterns Without Injection}

In order to establish a baseline model for comparison, results corresponding to the design flow rate 
were obtained. Under these conditions, velocity profiles were investigated at various vaned diffuser planes for evidence of flow separation.

In Fig. 2, the design flow velocity vector plot of the entire flow field is shown at a plane $0.8988 \mathrm{~mm}$ away from the shroud side wall. This figure shows that even at the design flow, the top or suction surface of the vaneless diffuser and the bottom or pressure surface of the vaned diffuser showed some evidence of flow deceleration. The development of this weak flow region at the pressure surface of the vaned diffuser is attributed to the upward acceleration of the main flow into the vaned diffuser through the narrowed area between the separated flow region at the suction surface of the vaneless diffuser and the leading edge of the vaned diffuser. This resulted in a flow angle pointing towards the top surface of the vaned diffuser.

At $60 \%$ of the design flow the same shroud plane is shown in Fig. 3. It is clear from this figure that the decelerated flow region became somewhat larger. Figure 4 shows the pressure surface of the vaned diffuser at the same flow rate. This figure shows that flow reverses along the hub and shroud walls.

\section{Flow Patterns with Fluid Injection}

Various injection rates $(3 \%, 7 \%$, and $10 \%)$ were tested. The results showed that both $3 \%$, and $7 \%$ injection rates were effective in eliminating the

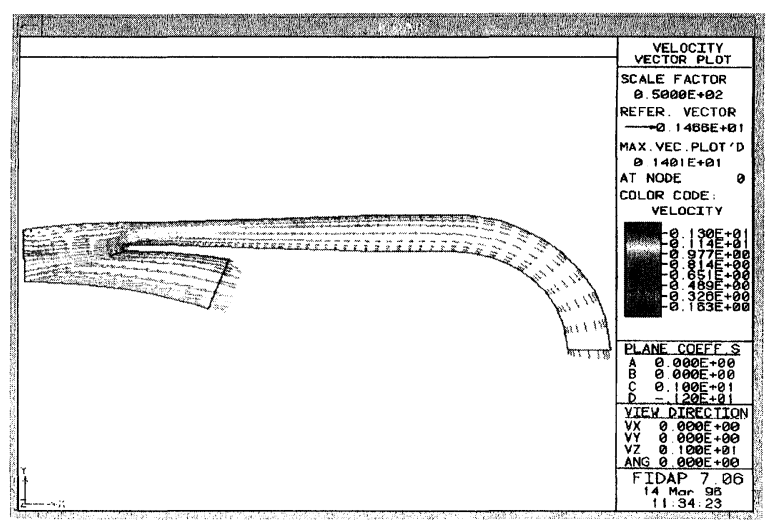

FIGURE 2 2-D view of the shroud plane velocity (design flow). separated flow region in the vaned diffuser at $60 \%$ of the design flow rate with no significant impact on the region at the suction surface of the vaneless diffuser. Figure 5 shows this result on the shroud wall plane for the $60 \%$ case with $3 \%$ injection rate. Figure 6 shows the results at the pressure surface at the same flow conditions. From these results it is clear that use of fluid injection completely restores separation-free flow conditions.

The possibility of inducing flow separation at the pressure surface of the vaned diffuser with higher injection rates was also investigated. It was determined that higher $(10 \%)$ injection flow rates can induce flow separation (Fig. 7). This is thought to

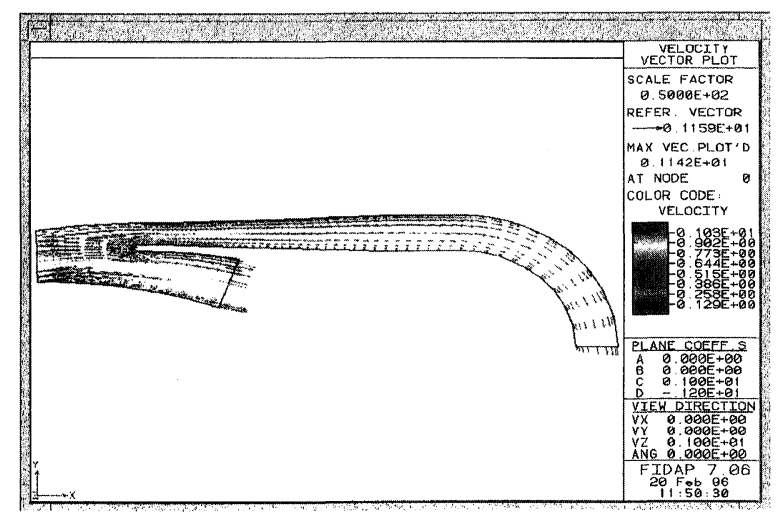

FIGURE 3 2-D view of the shroud plane velocity $(60 \%$ of design flow).

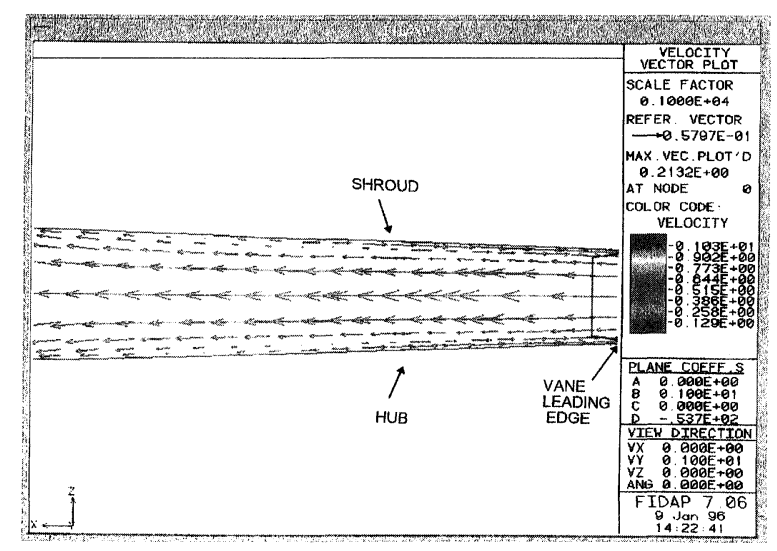

FIGURE 4 Vaned diffuser bottom plane velocity $(60 \%$ of design flow). 


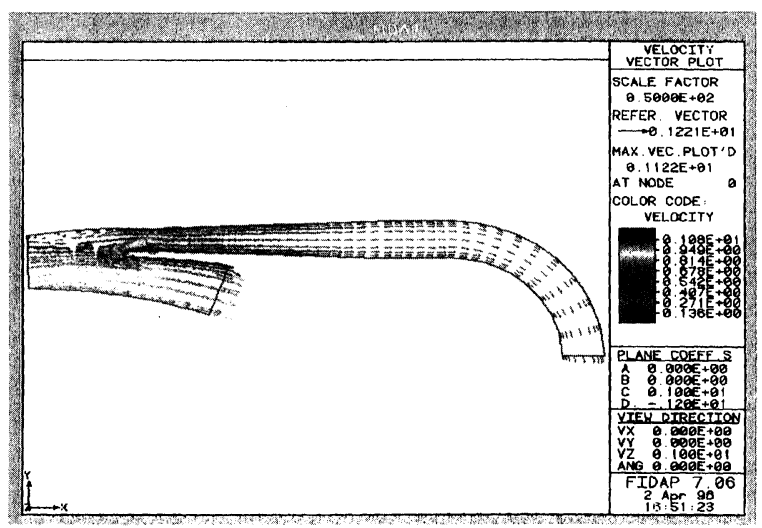

FIGURE 5 Vaned diffuser shroud plane velocity $(60 \%-3 \%$ injection).

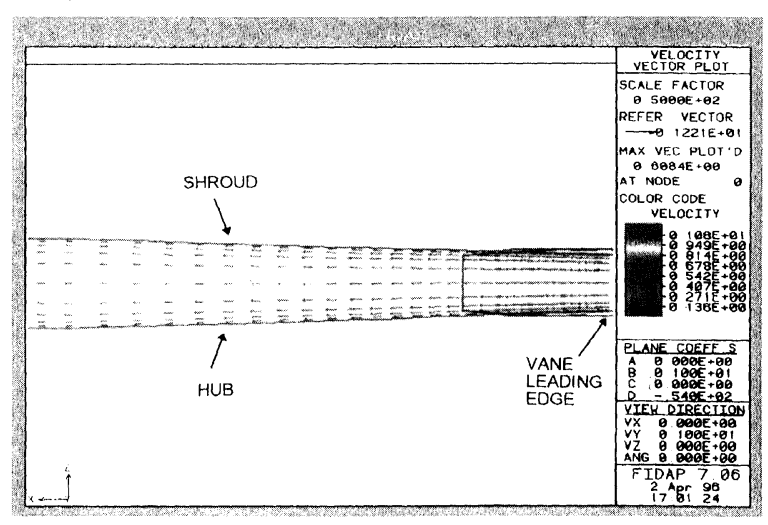

FIGURE 6 Vaned diffuser bottom plane velocity $(60 \%-3 \%$ injection).

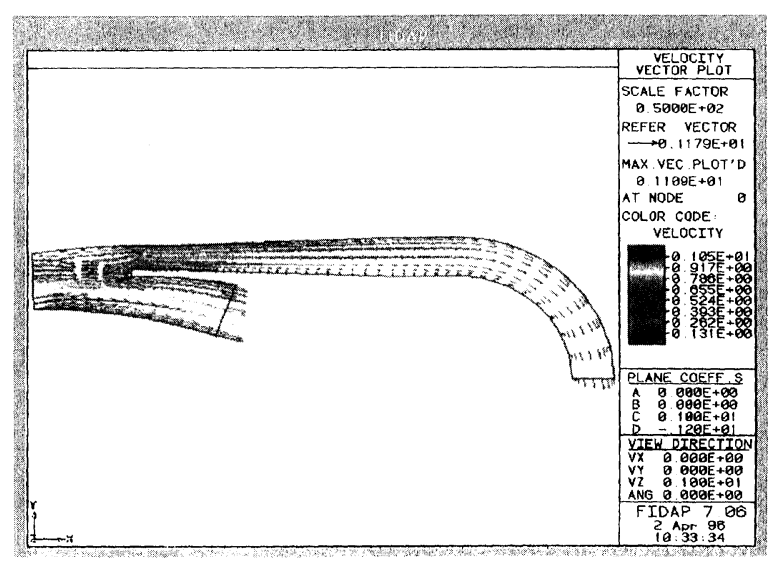

FIGURE 7 Vaned diffuser shroud plane velocity $(60 \%$ $10 \%$ injection).
TABLE III Pressure recovery characteristics

\begin{tabular}{lcc}
\hline Flow & $C_{p}(-)$ & Diff. eff. (\%) \\
\hline Ideal condition & 0.866 & 100 \\
$100 \%$ & 0.63 & 72 \\
$60 \%$ & 0.56 & 64 \\
$60 \%-3 \%$ injection & 0.68 & 78 \\
$60 \%-7 \%$ injection & 0.65 & 75 \\
$60 \%-10 \%$ injection & 0.55 & 63 \\
\hline
\end{tabular}

be the result of boundary layer "lift-off" by the flow coming through the first several injection slits. In this case injected flow augments the separated flow region instead of eliminating it. Bahl (1985) also reported that higher blowing velocities causes formation of a recirculation region.

\section{Pressure Recovery Without Fluid Injection}

Pressure recovery coefficients for both cases $(100 \%$, and $60 \%$ ) were determined from the vaned diffuser inlet and outlet pressures. These results are shown in Table III. As shown in this table, the pressure recovery coefficients for the $100 \%$, and $60 \%$ of the design flow were 0.63 , and 0.56 , respectively. The ideal pressure recovery coefficient for the vaned diffuser in this study was determined to be 0.866 , which indicates that there is significant room for improvement.

\section{Pressure Recovery with Fluid Injection}

With the employment of injection, there was clear evidence of improvement in pressure recovery in the vaned diffuser. These results are also shown in Table III for the $100 \%$, and $60 \%$ of the design flow conditions. As indicated in this table, for the $60 \%$ of the design flow, the injection rates of $3 \%$ achieved the highest pressure recovery.

These results show that there is a substantial improvement in pressure recovery over the cases without injection. Table III also shows the values of diffuser efficiency defined as $C_{p} / C_{p \text { i }}$ for both cases. 


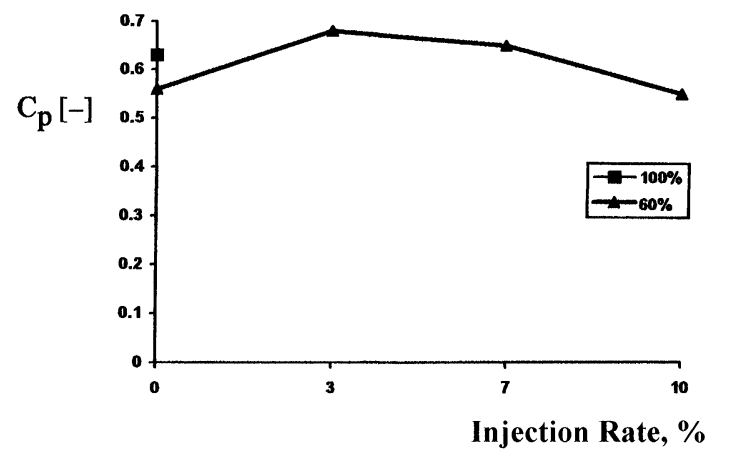

FIGURE 8 Pressure recovery coefficient.

\section{Optimal Injection Rate}

The results in Table III show that the pressure recovery coefficient, $C_{p}$ may have an optimal value corresponding to a particular fluid injection rate. The $C_{p}$ values were plotted against the injection rates and the results are shown in Fig. 8. This figure shows that an injection rate of $3 \%$ at $60 \%$ of the design flow rate may provide the highest pressure recovery while completely removing the separated flow region.

\section{CONCLUSIONS}

- A vaned diffuser operating at off-design flow conditions can experience flow separation.

- The application of fluid $\left(\mathrm{LH}_{2}\right)$ injection was shown to be an effective method for controlling the growth of the boundary layer and eliminating the resulting flow separation in a vaned diffuser at off-design flow conditions.

- By employment of optimum injection rates, diffuser efficiency was improved by as much as $21 \%$ at $60 \%$ off-design flow conditions.

- It can also be concluded that there is an 'optimal' injection rate corresponding to the highest pressure recovery at an off-design flow rate.

- Higher rates of flow injection can augment the separated flow region in a vaned diffuser.

\section{NOMENCLATURE}

\begin{tabular}{|c|c|}
\hline $\mathrm{AR}$ & area ratio \\
\hline$b$ & diffuser throat depth \\
\hline$c_{1,2}$ & $\begin{array}{l}\text { empirical constants in } \varepsilon \\
\text { and } k \text { equations }\end{array}$ \\
\hline$C_{\mu}$ & $\begin{array}{l}\text { empirical constant in } \\
\text { viscosity model }\end{array}$ \\
\hline$C_{p}$ & pressure recovery coefficient \\
\hline$C_{p \mathrm{i}}$ & $\begin{array}{l}\text { ideal pressure recovery } \\
\text { coefficient }\end{array}$ \\
\hline E & $\begin{array}{l}\text { empirical constant } \\
\text { (roughness parameter) }\end{array}$ \\
\hline$F$ & body force \\
\hline$G$ & shear generation term \\
\hline$k$ & turbulent kinetic energy \\
\hline$L$ & diffuser wall length \\
\hline $\mathrm{LH}_{2}$ & Liquid Hydrogen \\
\hline$N$ & axial diffuser length \\
\hline$P$ & fluid pressure \\
\hline $\operatorname{Re}$ & Reynolds number \\
\hline$u_{i}$ & velocity in $i$-direction \\
\hline$u^{+}$ & $\begin{array}{l}\text { dimensionless velocity } \\
\left(=u / u^{*}\right)\end{array}$ \\
\hline$u^{*}$ & $\begin{array}{l}\text { friction velocity } \\
\left(=\tau^{*} / \rho\right)^{1 / 2}\end{array}$ \\
\hline$V$ & $\begin{array}{l}\text { vaneless diffuser inlet } \\
\text { fluid velocity }\end{array}$ \\
\hline$V_{r}$ & radial component of velocity \\
\hline$V_{\theta}$ & tangential component of velocity \\
\hline$V_{t}$ & diffuser throat fluid velocity \\
\hline$W_{1}$ & diffuser throat width \\
\hline$W_{2}$ & diffuser exit width \\
\hline$y$ & coordinate distance \\
\hline$y^{+}$ & $\begin{array}{l}\text { dimensionless coordinate distance } \\
\left(=\rho u^{*} y / \mu\right)\end{array}$ \\
\hline
\end{tabular}

\section{Greek Letters}

$\epsilon \quad$ dissipation rate of $k$

$2 \theta \quad$ diffuser divergence angle

$\kappa \quad$ von Karman constant

$\mu \quad$ fluid viscosity 


$\begin{array}{ll}\mu_{\mathrm{t}} & \text { eddy viscosity } \\ \rho & \text { fluid density } \\ -\overline{\rho u_{i}^{\prime} u_{j}^{\prime}} & \text { Reynolds stress term } \\ \tau_{k} & \text { turbulent Prandtl number } \\ \tau_{\varepsilon} & \text { turbulent Schmidt number } \\ \tau_{\text {tot }} & \text { total shear stress } \\ \tau^{*} & \text { wall shear stress }\end{array}$

\section{Acknowledgment}

This work was supported by a grant from NASA Lewis Research Center, Cleveland, $\mathrm{OH}$, Grant No: NAG3-1153.

\section{References}

Bahl, R., 1985. Boundary layer blowing, AIAA Journal, 23(1), 157-158.
Ball, W.H., 1983. Experimental investigation of the effects of wall suction and blowing on the performance of highly offset diffusers, AIAA, SAE, and ASME, 19th Joint Propulsion Conference.

Kline, S.J. and Fox, R.W., 1962. Flow regime data and design methods for curved subsonic diffusers, ASME, Journal of Basic Engineering, 84, 303-312.

Lariviere, B.W., 1989. MK49-F Fuel pump diffuser and crossover design, Rockwell International, Rocketdyne Division $\mathrm{R} / \mathrm{H} 1173-4126$.

Lariviere, B.W. and Prueger, G.H., 1989. Performance tests of a high velocity ratio diffusing crossover, JANNAF Propulsion Meeting, Cleveland, $\mathrm{OH}$.

Muggli, F.A., Wiss, D., Eisele, K., Zhang, Z., Casey, M.V. and Galpin, P., 1996. Unsteady flow in the vaned diffuser of a medium specific speed pump, ASME/IGTI GT Conference, Birmingham, England.

Ogut, A. and Yoshida, B.R., 1994. CFD Analysis of flow in turbopump diffuser with wall suction, ASME Fluids Engineerin Division Summer Conference, FED-Vol. 196, pp. 295 315.

Schwendemann, M.F. and Sanders, B.W., 1982. Tangential blowing for control of the strong schock/boundary-layer interaction on inlet ramps, AIAA Paper No. 82, pp. 1082. 


\section{ait \\ ENERGY MATERIALS}

M A N E Y publishing

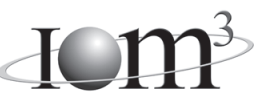

\section{Materials Science \& Engineering for Energy Systems}

Maney Publishing on behalf of the Institute of Materials, Minerals and Mining

The Institute of Materials, Minerals \& Mining

Economic and environmental factors are creating ever greater pressures for the efficient generation, transmission and use of energy. Materials developments are crucial to progress in all these areas: to innovation in design; to extending lifetime and maintenance intervals; and to successful operation in more demanding environments. Drawing together the broad community with interests in these areas, Energy Materials addresses materials needs in future energy generation, transmission, utilisation, conservation and storage. The journal covers thermal generation and gas turbines; renewable power (wind, wave, tidal, hydro, solar and geothermal); fuel cells (low and high temperature); materials issues relevant to biomass and biotechnology; nuclear power generation (fission and fusion); hydrogen generation and storage in the context of the 'hydrogen economy'; and the transmission and storage of the energy produced.

As well as publishing high-quality peer-reviewed research, Energy Materials promotes discussion of issues common to all sectors, through commissioned reviews and commentaries. The journal includes coverage of energy economics and policy, and broader social issues, since the political and legislative context influence research and investment decisions.

\section{CALL FOR PAPERS}

Contributions to the journal should be submitted online at http://ema.edmgr.com

To view the Notes for Contributors please visit: www.maney.co.uk/journals/notes/ema

Upon publication in 2006, this journal will be available via the Ingenta Connect journals service. To view free sample content online visit: www.ingentaconnect.com/content/maney

For further information please contact:

Maney Publishing UK

Tel: +44 (0)113 2497481 Fax: +44 (0)1132486983 Email: subscriptions@maney.co.uk

or

Maney Publishing North America

Tel (toll free): 8662975154 Fax: 6173546875 Email: maney@maneyusa.com

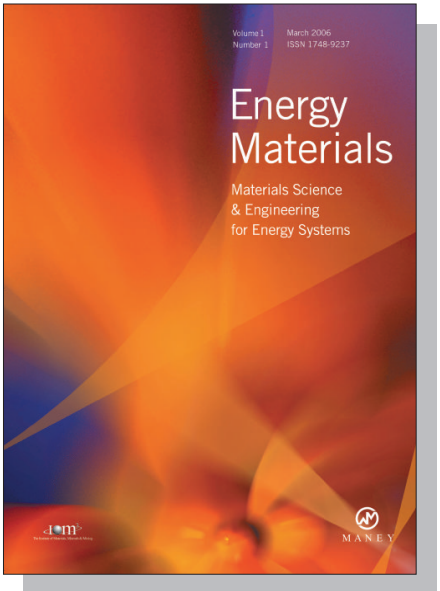

EDITORS

Dr Fujio Abe

NIMS, Japan

Dr John Hald, IPL-MPT, Technical University of Denmark, Denmark

Dr R Viswanathan, EPRI, USA

\section{SUBSCRIPTION INFORMATION}

Volume 1 (2006), 4 issues per year

Print ISSN: 1748-9237 Online ISSN: 1748-9245

Individual rate: $£ 76.00 / U S \$ 141.00$

Institutional rate: $£ 235.00 /$ US $\$ 435.00$

Online-only institutional rate: $£ 199.00 / U S \$ 367.00$

For special $\mathrm{IOM}^{3}$ member rates please email

subscriptions@maney.co.uk

\section{For further information or to subscribe online please visit www.maney.co.uk}



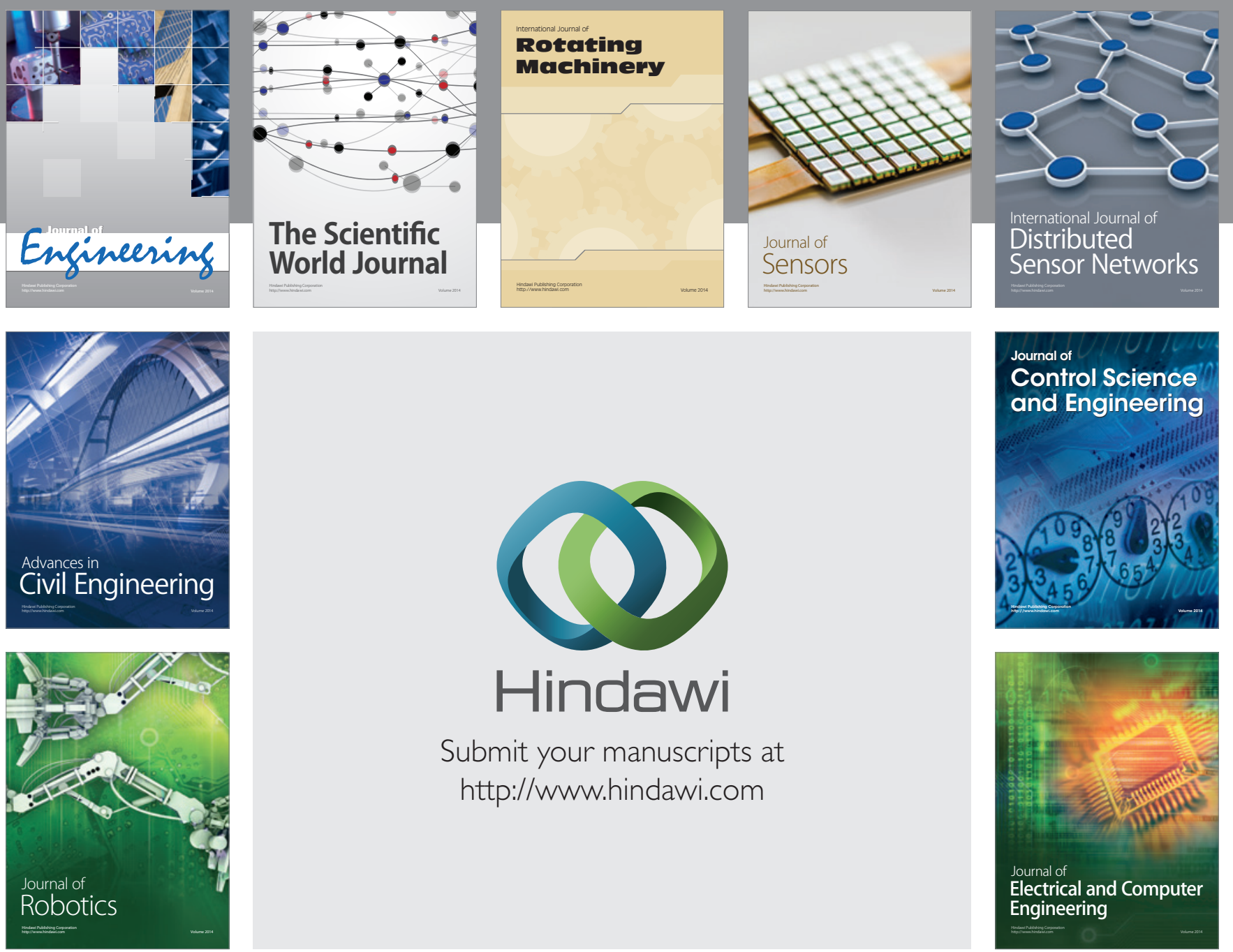

Submit your manuscripts at

http://www.hindawi.com
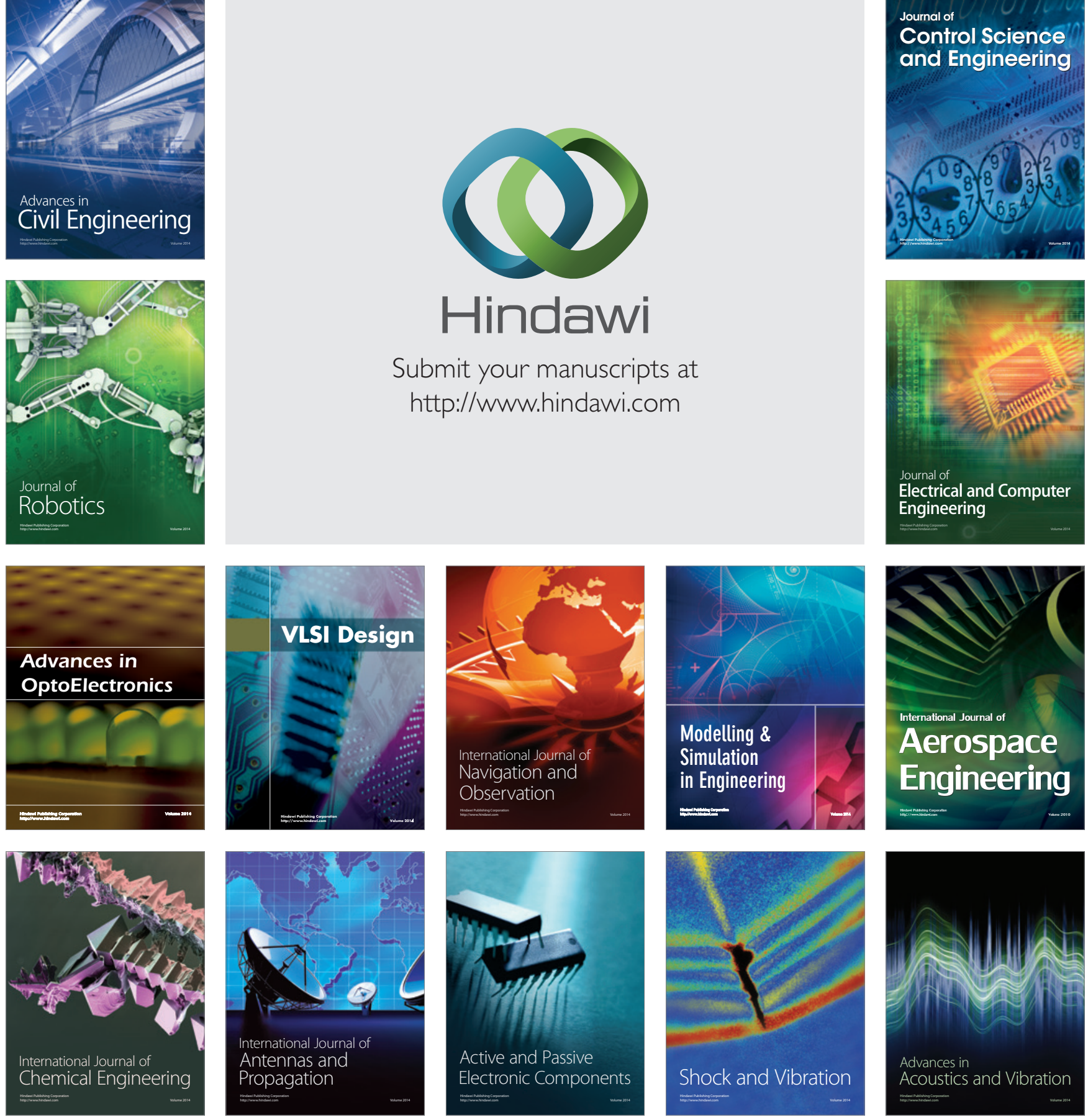